\title{
Hsp90 Inhibitor SNX-5422 Mesylate
}

National Cancer Institute

\section{Source}

National Cancer Institute. Hsp90 Inhibitor SNX-5422 Mesylate. NCI Thesaurus. Code C91068.

The orally bioavailable mesylate salt of a synthetic prodrug targeting the human heatshock protein 90 (Hsp90) with potential antineoplastic activity. Although the mechanism of action remains to be fully elucidated, Hsp90 inhibitor SNX-5422 is rapidly converted to SNX-2112, which accumulates more readily in tumors relative to normal tissues. SNX2112 inhibits Hsp90, which may result in the proteasomal degradation of oncogenic client proteins, including HER2/ERBB2, and the inhibition of tumor cell proliferation. $\mathrm{Hsp90}$ is a molecular chaperone that plays a key role in the conformational maturation of oncogenic signaling proteins, such as HER2/ERBB2, AKT, RAF1, BCR-ABL, and mutated p53, as well as many other molecules that are important in cell cycle regulation or immune responses. 